\title{
Relationships between peripheral reactive hyperemia index with coronary plaque burden and prognosis in patients with unstable angina pectoris complicated with type 2 diabetes mellitus
}

\author{
Xiyan Yang, Yu Xing, Kun Xia, Wenshu Zhao \\ Heart Center, Beijing Chaoyang Hospital, Capital Medical University \& Beijing Key Laboratory of Hypertension, Beijing, China \\ Contributions: (I) Conception and design: All authors; (II) Administrative support: All authors; (III) Provision of study materials or patients: All \\ authors; (IV) Collection and assembly of data: All authors; (V) Data analysis and interpretation: All authors; (VI) Manuscript writing: All authors; \\ (VII) Final approval of manuscript: All authors. \\ Correspondence to: Wenshu Zhao. Heart Center, Beijing Chaoyang Hospital, Capital Medical University \& Beijing Key Laboratory of Hypertension, \\ Beijing 100020, China. Email: zhaowenshu1965@126.com.
}

Background: Coronary plaque burden (CPB) is an important prognostic factor in patients with unstable angina pectoris (UAP). Our current study aims to investigate the relationships between peripheral reactive hyperemia index (RHI) with CPB and prognosis in patients with UAP complicated with type 2 diabetes mellitus (T2DM).

Methods: The clinical data of 187 UAP-T2DM patients who were treated in our center from June 2017 to January 2019 were retrospectively collected. RHI, CPB, and other clinical features were measured. The patients were followed up for 18 months and then divided into an adverse cardiovascular event (ACE) group ( $\mathrm{n}=71$, with ACEs) and a control group ( $\mathrm{n}=116$, without ACEs). The differences in RHI, CPB, and other clinical features between these two groups were compared, and the potential correlation between RHI and CPB was analyzed.

Results: Compared with the control group, the ACE group had significantly lower RHI $(1.21 \pm 0.32$ vs. $1.59 \pm 0.35, \mathrm{P}=0.000)$ and left ventricular ejection fraction (LVEF) $(42.92 \% \pm 7.78 \% v s .48 .90 \% \pm 6.76 \%$, $\mathrm{P}=0.000)$ and a significantly higher left ventricular myocardial mass index $(2.67 \pm 0.87$ vs. $2.27 \pm 0.49 \mathrm{mg} / \mathrm{g}$, $\mathrm{P}=0.000)$, carotid intima-media thickness $(1.65 \pm 0.34$ vs. $1.51 \pm 0.32 \mathrm{~mm}, \mathrm{P}=0.000)$, number of coronary plaques $(3.98 \pm 0.53$ vs. $3.32 \pm 0.38, \mathrm{P}=0.000)$, non-calcified plaque volume $\left(32.89 \pm 12.56\right.$ vs. $22.58 \pm 9.97 \mathrm{~mm}^{3}$, $\mathrm{P}=0.000)$, calcified plaque volume $\left(4.89 \pm 1.29\right.$ vs. $\left.3.88 \pm 1.05 \mathrm{~mm}^{3}, \mathrm{P}=0.000\right)$, non-calcified plaque burden $(5.70 \% \pm 1.60 \%$ vs. $3.18 \% \pm 1.08 \%, \mathrm{P}=0.000)$, and calcified plaque burden $(0.90 \% \pm 0.22 \%$ vs. $0.65 \% \pm 0.19 \%$, $\mathrm{P}=0.000)$. Pearson linear correlation analysis showed that peripheral RHI was negatively correlated with plaque number, non-calcified plaque volume, calcified plaque volume, non-calcified plaque burden, and calcified plaque burden in patients with UAP complicated with T2DM (all $\mathrm{P}<0.05$ ).

Conclusions: Decreased peripheral RHI is associated with ACEs and CPB in patients with UAP complicated with T2DM.

Keywords: Reactive hyperemia index (RHI); coronary plaque burden (CPB); unstable angina pectoris; type 2 diabetes mellitus (T2DM)

Submitted Sep 23, 2020. Accepted for publication Apr 22, 2021.

doi: $10.21037 / \mathrm{atm}-21-657$

View this article at: http://dx.doi.org/10.21037/atm-21-657 


\section{Introduction}

Type 2 diabetes mellitus (T2DM) is becoming more prevalent, especially in younger populations, as dietary and lifestyle habits change (1-4). Since T2DM is often asymptomatic in its early stages, many patients have poor compliance to treatment. Over time, poorly controlled T2DM can lead to various cardiovascular diseases. For instance, unstable angina pectoris (UAP) is a clinically common complication in T2DM patients. Patients with UAP are more likely to develop adverse cardiovascular events (ACEs), which are also the main risk factors for poor prognosis. In recent years, it has been found that coronary plaque burden $(\mathrm{CPB})$ is closely related to the prognosis of patients with UAP (5). Coronary stenosis occurs when CPB increases, after which patients are more likely to develop angina symptoms. Even worse, unstable coronary plaques can easily break off and cause myocardial infarction, leading to death in severe cases (6). Therefore, it is important to explore CPB and its relevant factors in patients with T2DM and UAP. Reactive hyperemia index (RHI) is currently considered a noninvasive indicator for assessing vascular endothelial function. Measured by changes in peripheral arterial tone, RHI is a valuable prognostic factor for many cardiovascular diseases (7-10). We hypothesized that RHI might be associated with CPB in patients with T2DM and UAP. As few relevant studies have been performed, we conducted our current study. We present the following article in accordance with the STROBE reporting checklist (available at http://dx.doi.org/10.21037/atm-21-657).

\section{Methods}

\section{Subject data}

The clinical data of 187 UAP-T2DM patients who were treated in our center from June 2017 to January 2019 were retrospectively collected. The patients were followed up for 18 months and then divided into an ACE group ( $\mathrm{n}=71$, with ACEs) and a control group ( $\mathrm{n}=116$, without ACEs). The inclusion criteria were as follows: (I) with T2DM; (II) with UAP; (III) aged 30-70 years; and (IV) agreed to take part in this research. The exclusion criteria included the following: (I) with malignant tumors; (II) with primary cardiac lesions;(III) loss to follow-up, transfers to other clinics, or non-cooperation with treatment during the follow-up period; and (V) occurrence of other serious unexpected events unrelated to the treatment that could affect the observation results. The general data, including age, sex, body mass index (BMI), history of smoking, and history of alcoholism, were matched between the two groups (all $\mathrm{P}>0.05$ ) (Table 1). The Ethics Committee approved the study of Beijing Chaoyang Hospital, Capital Medical University (no. 2020-Sci-527). All procedures performed in this study involving human participants were in accordance with the Declaration of Helsinki (as revised in 2013). Individual consent for this retrospective analysis was waived.

\section{Main measures}

\section{RHI}

RHI was measured with an EndoPAT-2000 Noninvasive Diagnostic System (Itamar, Israel). Briefly, the patient was asked to take a supine position after resting for 10 minutes; the sensors were nested at the tips of both index fingers, and the cuff was placed $2 \mathrm{~cm}$ distal to the left elbow joint over the brachial artery. After the arterial tone data were collected within 5 minutes, the cuff was inflated to $180 \mathrm{mmHg}$ to block the brachial artery for 5 minutes; then, the cuff was quickly deflated, and the arterial tone data were recorded. RHI was calculated accordingly.

\section{CPB}

Intracoronary optical coherence tomography (OCT) was applied to measure $\mathrm{CPB}$ in terms of the number of plaques, non-calcified plaque volume, calcified plaque volume, noncalcified plaque burden, and calcified plaque burden (Figure 1).

\section{Other clinical indicators}

Other clinical indicators include left ventricular ejection fraction (LVEF), mean ventricular wall stress, left ventricular myocardial mass index, end-systolic volume, end-diastolic volume, New York Heart Association (NYHA) class, carotid intima-media thickness (CIMT), homocysteine, and brain natriuretic peptide (BNP).

\section{Treatment}

All patients were given hypoglycemic medications. A combination of multiple drugs or insulin was used to control blood glucose when necessary. Patients were instructed to improve their lifestyles (e.g., adhere to low-salt and lowfat diabetic diets). Aspirin and clopidogrel were prescribed. Statins were applied for lipid control. Percutaneous 
Table 1 General data in the two groups

\begin{tabular}{lcccccc}
\hline Group & $\mathrm{n}$ & Age & Sex (proportion of females) & History of smoking & History of alcoholism & $\mathrm{BMl}\left(\mathrm{kg} / \mathrm{m}^{2}\right)$ \\
\hline ACE group & 71 & $58.37 \pm 5.73$ & $34(47.89 \%)$ & $21(29.58 \%)$ & $12(16.90 \%)$ & $26.32 \pm 3.87$ \\
Control group & 116 & $58.93 \pm 6.02$ & $56(48.28 \%)$ & $32(27.59 \%)$ & $20(17.24 \%)$ & $26.18 \pm 4.02$ \\
$t / \chi^{2}$ value & - & 0.629 & 0.003 & 0.086 & 0.004 & 0.234 \\
P value & - & 0.530 & 0.959 & 0.769 & 0.952 & 0.815 \\
\hline
\end{tabular}

BMI, body mass index; ACE, adverse cardiovascular event.

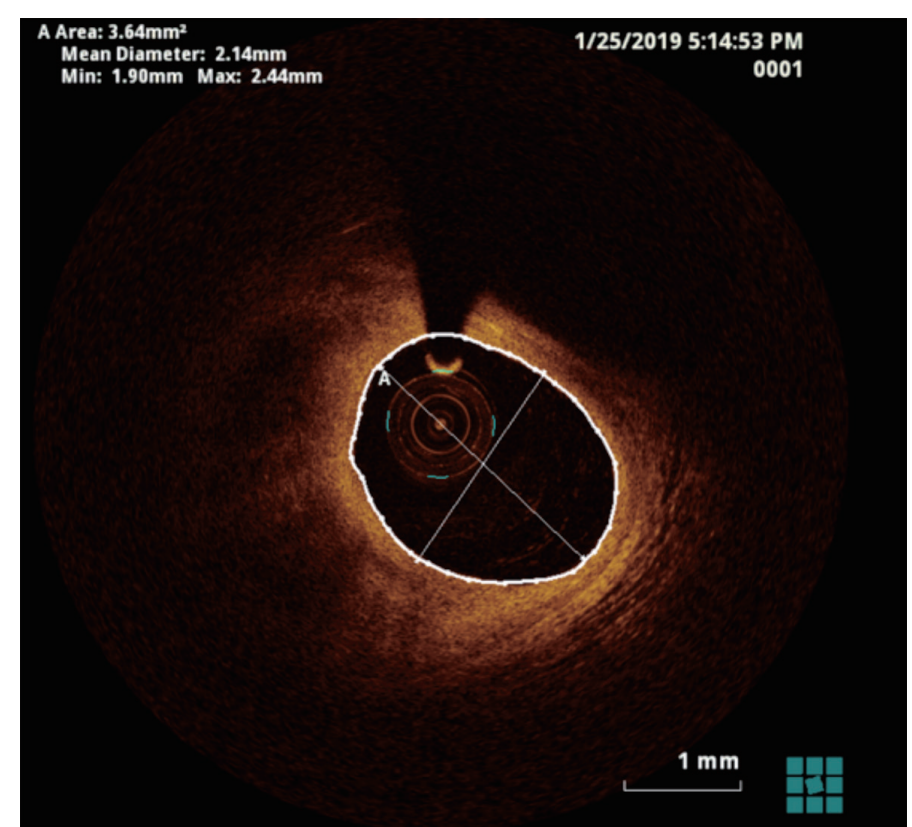

Figure 1 A 67 -year-old female patient with a $\mathrm{CPB}$ of $66 \%$. CPB, coronary plaque burden.

coronary artery stenting was performed if necessary.

\section{Definition of ACE}

An ACE was identified if the patient experienced angina pectoris, cardiac insufficiency, incidental malignant arrhythmia, malignant arrhythmia, recurrent myocardial infarction, heart failure, or cardiac arrest. ACEs in our 71 patients included malignant arrhythmias $(n=46)$, cardiac insufficiency $(\mathrm{n}=6)$, incidental malignant arrhythmias $(\mathrm{n}=12)$, recurrent myocardial infarction $(n=4)$, heart failure $(n=2)$, and cardiac arrest $(\mathrm{n}=1)$.

\section{Statistical analysis}

Statistical analysis was performed with the SPSS 22.0 software package (IBM Corp., USA), and a P value of less than 0.05 was considered statistically significant. The normally distributed measurement data are presented using mean \pm standard deviations and were compared with the $t$-test. The count data are expressed as $\mathrm{n}(\%)$ and were compared with the chi-square test. The potential correlation between the two measurements was analyzed by Pearson linear correlation.

\section{Results}

\section{Comparisons of homocysteine, BNP, and RHI between the} two groups

While homocysteine and BNP showed no significant difference between these two groups (both $\mathrm{P}>0.05$ ), RHI was significantly lower in the ACE group than in the 
Table 2 Comparisons of homocysteine, BNP, and RHI between the two groups

\begin{tabular}{lcccc}
\hline Group & $\mathrm{n}$ & Homocysteine $(\mathrm{mmol} / \mathrm{L})$ & $\mathrm{BNP}(\mathrm{ng} / \mathrm{L})$ & $\mathrm{RHI}$ \\
\hline ACE group & 71 & $18.21 \pm 4.65$ & $1,446.21 \pm 354.83$ & $1.21 \pm 0.32$ \\
Control group & 116 & $17.89 \pm 3.74$ & $1,435.82 \pm 374.90$ & $1.59 \pm 0.35$ \\
$t$ value & - & 0.517 & 0.188 & 7.440 \\
P value & - & 0.606 & 0.851 & 0.000 \\
\hline
\end{tabular}

$\mathrm{BNP}$, brain natriuretic peptide; $\mathrm{RHI}$, reactive hyperemia index; $\mathrm{ACE}$, adverse cardiovascular event.

Table 3 Comparison of cardiovascular functions between two groups

\begin{tabular}{lcccc}
\hline Group & $\mathrm{n}$ & $\begin{array}{c}\text { Left ventricular ejection } \\
\text { fraction }(\%)\end{array}$ & $\begin{array}{c}\text { Left ventricular myocardial } \\
\text { mass index }(\mathrm{mg} / \mathrm{g})\end{array}$ & $\begin{array}{c}\text { Carotid intima-media } \\
\text { thickness }(\mathrm{CIMT})(\mathrm{mm})\end{array}$ \\
\hline ACE group & 71 & $42.92 \pm 7.78$ & $2.67 \pm 0.87$ & $1.65 \pm 0.34$ \\
Control group & 116 & $48.90 \pm 6.76$ & $2.27 \pm 0.49$ & $1.51 \pm 0.32$ \\
$t$ value & - & 5.540 & 4.022 & 2.835 \\
P value & - & 0.000 & 0.000 & 0.005 \\
\hline
\end{tabular}

ACE, adverse cardiovascular event.

Table 4 Comparisons of CPB between two groups

\begin{tabular}{lcccccc}
\hline Group & $\mathrm{n}$ & $\begin{array}{c}\text { Number of coronary } \\
\text { plaques }\end{array}$ & $\begin{array}{c}\text { Non-calcifie plaque } \\
\text { volume }\left(\mathrm{mm}^{3}\right)\end{array}$ & $\begin{array}{c}\text { Calcified plaque } \\
\text { volume }\left(\mathrm{mm}^{3}\right)\end{array}$ & $\begin{array}{c}\text { Non-calcifie plaque } \\
\text { burden }(\%)\end{array}$ & $\begin{array}{c}\text { Calcified plaque } \\
\text { burden }(\%)\end{array}$ \\
\hline ACE group & 71 & $3.98 \pm 0.53$ & $32.89 \pm 12.56$ & $4.89 \pm 1.29$ & $5.70 \pm 1.60$ & $0.90 \pm 0.22$ \\
Control group & 116 & $3.32 \pm 0.38$ & $22.58 \pm 9.97$ & $3.88 \pm 1.05$ & $3.18 \pm 1.08$ & $0.65 \pm 0.19$ \\
$t$ value & - & 9.892 & 6.206 & 5.862 & 12.874 & 0.000 \\
P value & - & 0.000 & 0.000 & 0.000 & 0.000 \\
\hline
\end{tabular}

CPB, coronary plaque burden; ACE, adverse cardiovascular event.

control group $(1.21 \pm 0.32$ vs. $1.59 \pm 0.35, \mathrm{P}=0.000)$ (Table 2$)$.

\section{Comparison of cardiovascular functions between the two groups}

Compared with the control group, the ACE group had significantly lower LVEF $(42.92 \% \pm 7.78 \%$ vs. $48.90 \% \pm 6.76 \%$, $\mathrm{P}=0.000$ ), higher left ventricular myocardial mass index (2.67 \pm 0.87 vs. $2.27 \pm 0.49 \mathrm{mg} / \mathrm{g}, \mathrm{P}=0.000$ ), and higher CIMT (1.65 \pm 0.34 vs. $1.51 \pm 0.32 \mathrm{~mm}, \mathrm{P}=0.005$ ) (Table 3).

\section{Comparison of CPB between the two groups}

Compared with the control group, the ACE group showed a significant increase in the number of coronary plaques
(3.98 \pm 0.53 vs. $3.32 \pm 0.38, \mathrm{P}=0.000)$, non-calcified plaque volume $\left(32.89 \pm 12.56\right.$ vs. $\left.22.58 \pm 9.97 \mathrm{~mm}^{3}, \mathrm{P}=0.000\right)$, calcified plaque volume $\left(4.89 \pm 1.29\right.$ vs. $3.88 \pm 1.05 \mathrm{~mm}^{3}$ $\mathrm{P}=0.000)$, non-calcified plaque burden $(5.70 \% \pm 1.60 \%$ vs. $3.18 \% \pm 1.08 \%, \mathrm{P}=0.000)$, and calcified plaque burden $(0.90 \% \pm 0.22 \%$ vs. $0.65 \% \pm 0.19 \%, \mathrm{P}=0.000$; Table 4$)$.

\section{Relationships of peripheral RHI with CPB in patients with UAP complicated with T2DM}

Pearson linear correlation analysis showed that peripheral RHI was negatively correlated with plaque number, noncalcified plaque volume, calcified plaque volume, noncalcified plaque burden, and calcified plaque burden in patients with UAP complicated with $\mathrm{T} 2 \mathrm{DM}$ (all $\mathrm{P}<0.05$; 
Table 5 Relationships of peripheral RHI with CPB in patients with UAP complicated with T2DM

\begin{tabular}{|c|c|c|c|c|c|}
\hline Group & $\begin{array}{c}\text { Number of coronary } \\
\text { plaques }\end{array}$ & $\begin{array}{l}\text { Non-calcifie plaque } \\
\text { volume }\end{array}$ & Calcified plaque volume & $\begin{array}{c}\text { Non-calcifie plaque } \\
\text { burden (\%) }\end{array}$ & $\begin{array}{c}\text { Calcified plaque } \\
\text { burden (\%) }\end{array}$ \\
\hline$r$ value & -0.435 & -0.573 & -0.442 & -0.593 & -0.398 \\
\hline$P$ value & 0.002 & 0.000 & 0.001 & 0.000 & 0.010 \\
\hline
\end{tabular}

$\mathrm{RHI}$, reactive hyperemia index; CPB, coronary plaque burden; UAP, unstable angina pectoris; T2DM, type 2 diabetes mellitus.

Table 5).

\section{Discussion}

Impairment of vascular endothelial cell function is the basis of the pathogenesis of most cardiovascular diseases. Pathophysiologically, cardiovascular function impairment caused by T2DM leads to atherosclerosis and vascular endothelial cell function impairment, which can eventually induce angina pectoris, myocardial infarction, stroke, and other cardiovascular diseases. Oral hypoglycemics (e.g., saxagliptin) are recognized as effective and safe; their main adverse effect is headache, which most patients can gradually tolerate. Peripheral RHI, a recently developed noninvasive index for measuring vascular endothelial function, can well reflect the endothelial cell-mediated diastolic effect. A decreased peripheral RHI indicates vascular endothelial cell functional impairment, and a higher RHI value often shows the good compensatory function of endothelial cells $(10,11)$. Our current study was designed to investigate the correlations of peripheral RHI with plaque burden and prognosis in patients with UAP complicated with T2DM. The results showed that peripheral RHI was significantly associated with ACE and CPB occurrence in these patients.

Pathophysiologically, UAP patients typically have coronary artery disease (e.g., coronary stenosis), which leads to inadequate myocardial blood supply, leading to the onset and progression of angina. The main cause of coronary stenosis is the formation of coronary plaques (12-14), which can be subdivided into calcified and, predominantly, non-calcified plaques. With cholesterol being its main component, a non-calcified plaque has only a thin outer fibrous cap and is rich in inflammatory factors and macrophages, which can release proteases and other factors to dissolve the fibrous cap; consequently, the noncalcified plaques can be easily dislodged from the artery wall and block coronary branches, leading to ACEs, including myocardial infarction and heart failure (15). Although the calcified plaques are more stable, a large number of calcified plaques can also lead to obstruction of coronary blood flow, leading to the occurrence and progression of UAP. Thus, CPB plays a key role in developing ACEs in patients with T2DM complicated with UAP. Increased CPB suggests more severe atherosclerosis and impairment of vascular endothelial cell function. Peripheral RHI is an important predictor of vascular endothelial cell functional impairment (16), and there is a correlation between peripheral RHI and $\mathrm{CPB}$, as demonstrated in our current study. In our current study, peripheral RHI was correlated with RHI and CPB in patients with UAP complicated with T2DM. The possible mechanism responsible for this is chronic intravascular inflammation in patients with UAP complicated with T2DM, leading to vascular endothelial function impairment and atherosclerosis (17-19), which manifest as an increase in peripheral RHI. Endothelial cell damage and further development of atherosclerosis can lead to coronary plaque formation, and ACE occurs when the plaque breaks off.

However, limited by its retrospective design, our current study did not investigate the correlation between RHI and coronary microvascular dysfunction, and its sample size was relatively small. In summary, decreased peripheral RHI is associated with ACEs and CPB in patients with UAP complicated with T2DM.

\section{Acknowledgments}

Funding: None.

\section{Footnote}

Reporting Checklist: The authors have completed the STROBE reporting checklist. Available at http://dx.doi. org/10.21037/atm-21-657

Data Sharing Statement: Available at http://dx.doi. org/10.21037/atm-21-657 
Conflicts of Interest: All authors have completed the ICMJE uniform disclosure form (available at http://dx.doi. org/10.21037/atm-21-657). The authors have no conflicts of interest to declare.

Ethical Statement: The authors are accountable for all aspects of the work in ensuring that questions related to the accuracy or integrity of any part of the work are appropriately investigated and resolved. The Ethics Committee approved the study of Beijing Chaoyang Hospital, Capital Medical University (no. 2020-Sci-527). All procedures performed in this study involving human participants were in accordance with the Declaration of Helsinki (as revised in 2013). Individual consent for this retrospective analysis was waived.

Open Access Statement: This is an Open Access article distributed in accordance with the Creative Commons Attribution-NonCommercial-NoDerivs 4.0 International License (CC BY-NC-ND 4.0), which permits the noncommercial replication and distribution of the article with the strict proviso that no changes or edits are made and the original work is properly cited (including links to both the formal publication through the relevant DOI and the license). See: https://creativecommons.org/licenses/by-nc-nd/4.0/.

\section{References}

1. Regmi D, Al-Shamsi S, Govender RD, et al. Incidence and risk factors of type 2 diabetes mellitus in an overweight and obese population: a long-term retrospective cohort study from a Gulf state. BMJ Open 2020;10:e035813.

2. Accordino MK, Wright JD, Buono D, et al. Incidence and Predictors of Diabetes Mellitus after a Diagnosis of EarlyStage Breast Cancer in the Elderly Using Real-World Data. Breast Cancer Res Treat 2020;183:201-11.

3. Han $Y$, Zhang $S$, Chen $S$, et al. Incidence and risk factors of type 2 diabetes mellitus in individuals with different fasting plasma glucose levels. Ther Adv Endocrinol Metab 2020;11:2042018820928844.

4. Lopez-de-Andres A, Albaladejo-Vicente R, de MiguelDiez J, et al. Incidence and outcomes of hospitalization for community-acquired, ventilator-associated and nonventilator hospital-acquired pneumonias in patients with type 2 diabetes mellitus in Spain. BMJ Open Diabetes Res Care 2020;8:e01447.

5. Chai D, Kong X, Lu S, et al. CD4+/CD8+ ratio positively correlates with coronary plaque instability in unstable angina pectoris patients but fails to predict major adverse cardiovascular events. Ther Adv Chronic Dis 2020;11:2040622320922020.

6. Sakaguchi M, Ehara S, Hasegawa T, et al. Coronary plaque rupture with subsequent thrombosis typifies the culprit lesion of non-ST-segment-elevation myocardial infarction, not unstable angina: non-ST-segment-elevation acute coronary syndrome study. Heart Vessels 2017;32:241-51.

7. Koshiba H, Maeshima E. Acute effects of moderateintensity cycling exercise on endothelial function in young healthy men: An investigation using the reactive hyperemia index. Technol Health Care 2021;29:317-22.

8. Motozato K, Suematsu Y, Norimatsu K, et al. Reactive Hyperemia Index Associated With Atherosclerotic Cardiovascular Disease Under Treatment for Lifestyle Diseases. J Clin Med Res 2020;12:293-9.

9. Saito Y, Kitahara H, Nishi T, et al. Systemic endothelial dysfunction in patients with vasospastic and microvascular angina: serum uric acid as a marker of reactive hyperemia index. Coron Artery Dis 2020;31:565-6.

10. He Y, Cheng XF, Wang K, et al. Predictive value of combining the SYNTAX score with reactive hyperemia index in patients with acute coronary syndrome undergoing percutaneous coronary intervention. Catheter Cardiovasc Interv 2020;95:E130-9.

11. Kobayashi H, Okada A, Tabata H, et al. Association between reactive hyperemia peripheral arterial tonometry index and atrial fibrillation recurrence after catheter ablation. Int J Cardiol Heart Vasc 2019;24:100385.

12. Mazzone A, Clemente A, Sbrana S, et al. Statins association with calcification in coronary plaque and heart valves: a possible different clinical significance: Montignoso HEart and Lung Project (MHELP) study preliminary data in primary cardiovascular prevention. Eur J Prev Cardiol 2020. [Epub ahead of print]. doi: 10.1177/2047487320932330.

13. Williams MC, Kwiecinski J, Doris M, et al. LowAttenuation Noncalcified Plaque on Coronary Computed Tomography Angiography Predicts Myocardial Infarction: Results From the Multicenter SCOT-HEART Trial (Scottish Computed Tomography of the HEART). Circulation 2020;141:1452-62.

14. van Rosendael AR, Lin FY, Ma X, et al. Percent atheroma volume: Optimal variable to report wholeheart atherosclerotic plaque burden with coronary CTA, the PARADIGM study. J Cardiovasc Comput Tomogr 2020;14:400-6. 
15. Hong YJ, Jeong MH, Choi YH, et al. Predictors of noreflow after percutaneous coronary intervention for culprit lesion with plaque rupture in infarct-related artery in patients with acute myocardial infarction. J Cardiol 2009;54:36-44.

16. Tuttolomondo A, Petta S, Casuccio A, et al. Reactive hyperemia index (RHI) and cognitive performance indexes are associated with histologic markers of liver disease in subjects with non-alcoholic fatty liver disease (NAFLD): a case control study. Cardiovasc Diabetol 2018;17:28.

17. Ruiz-García A, Arranz-Martínez E, Morón-Merchante I, et al. Consensus document of the Spanish Society of Arteriosclerosis (SEA) for the prevention and treatment

Cite this article as: Yang X, Xing Y, Xia K, Zhao W. Relationships between peripheral reactive hyperemia index with coronary plaque burden and prognosis in patients with unstable angina pectoris complicated with type 2 diabetes mellitus. Ann Transl Med 2021;9(8):655. doi: 10.21037/atm-21-657 of cardiovascular disease in type 2 diabetes mellitus. Clin Investig Arterioscler 2018;30 Suppl 1:1-19.

18. Namekata T, Shirai K, Tanabe N, et al. Estimating the extent of subclinical arteriosclerosis of persons with prediabetes and diabetes mellitus among Japanese urban workers and their families: a cross-sectional study. BMC Cardiovasc Disord 2016;16:52.

19. Gu PY, Kang DM, Wang WD, et al. Relevance of plasma obestatin and early arteriosclerosis in patients with type 2 diabetes mellitus. J Diabetes Res 2013;2013:563919.

(English Language Editor: J. Gray) 